\title{
Effects of Feeding Back the Motivation of a Collaboratively Learning Group
}

\section{Cornelia Schoor ${ }^{1}$, Salome Kownatzki ${ }^{2}$, Susanne Narciss ${ }^{2}$, \& Hermann Körndle ${ }^{2}$}
${ }^{1}$ Department of Educational Research, University of Bamberg, Bamberg ${ }^{2}$ Psychology of Learning and Instruction, TU Dresden, Dresden

\section{Germany}

Correspondence: Cornelia Schoor. University of Bamberg, Department of Educational Research, Markusplatz 3 , 96047 Bamberg. Germany. E-mail: cornelia.schoor@uni-bamberg.de

(C) Education \& Psychology I+D+i and Ilustre College of Psychology in eastern Andalusia (España) 


\begin{abstract}
Introduction. Motivation is an important issue in both face-to-face and computer-supported collaborative learning. There are several approaches for enhancing motivation, including group awareness tools that provide feedback on the group's motivation. However, this feedback was rarely unconfounded with other constructs. Additionally, it is only assumed and not investigated that the learners talk about their feedback and then remedy motivational problems which leads to the observed motivation gain.

Method. In our experimental study, triads worked on a collaborative learning task either with $(\mathrm{N}=33)$ or without $(\mathrm{N}=18)$ a motivational feedback tool. Triads with a feedback tool were either prompted to discuss their results or not. We assessed motivation and knowledge before and after their work.
\end{abstract}

Results. We found no effect of the feedback tool on motivation or knowledge. Whether feedback was discussed or not made no difference.

Discussion and Conclusion. These results indicate that a motivational feedback tool is only effective under specific circumstances which must be further researched.

Keywords: Motivation; feedback; awareness; cooperative learning; computer-supported collaborative learning

Received: 09/16/13 Initial acceptance: 10/10/13 Final acceptance: 03/26/14 


\section{Efectos de la Retroalimentación de la Motivación en un Grupo de Aprendizaje Colaborativo}

\section{Resumen}

Introducción. La motivación es un tema importante, tanto cara a cara como en equipo colaborativo. Existen varios enfoques para mejorar la motivación, incluidas las herramientas de sensibilización de grupos que proporcionan feedback sobre la motivación del grupo. Sin embargo, este feedback rara vez sin factores de confusión con otras construcciones. Además, sólo se ha supuesto y no investigado que los alumnos hablan con feedback y esto remedia los problemas de motivación, con un aumento observado de la motivación.

Método. En nuestro estudio experimental, tríadas trabajaban en una tarea de aprendizaje colaborativo, ya sea con $(\mathrm{N}=33)$ o $\sin (\mathrm{N}=18)$ de una herramienta de feedback motivacional. Las tríadas con una herramienta de feedback se vieron impulsados a hablar de sus resultados o no. Se evaluó la motivación y el conocimiento antes y después de su trabajo.

Resultados. No se encontraron efectos de la herramienta de feedback sobre la motivación o el conocimiento.

Discusión y Conclusión. Estos resultados indican que una herramienta de feedback motivacional sólo es eficaz en determinadas circunstancias que deben ser investigadas más a fondo.

Palabras Clave: motivación; feedback; conciencia; aprendizaje cooperativo; aprendizaje colaborativo asistido por ordenador 


\section{Introduction}

Computer-supported collaborative learning becomes more and more important in our world of distributed and just-in-time learning. However, keeping up the motivation in a cooperative group has always been a difficult task (c.f. Karau \& Williams, 1993; Kerr, 1983; Linnenbrink-Garcia, Rogat, \& Koskey, 2011; Shepperd, 1993). In a distributed group whose only means of communication is the computer, this might be an even more complex problem. It is a lot easier to let the other group members do all the work in the more anonymous setting of computer-supported collaborative learning (CSCL) than in a face-to-face setting (Hron, Hesse, \& Friedrich, 2002; c.f. Kreijns, Kirschner, \& Jochems, 2003). Therefore, supporting the motivation of a CSCL group is an important task for psychological research.

There has been research on the question of how to support the motivation of a cooperative learning group (e.g., Slavin, 1992). One approach is to directly influence the group's motivation, for example, by giving rewards (e.g., Slavin, 1992). However, a more subtle approach is to provide motivation feedback to the group members (c.f. research on group awareness, e.g. Bodemer \& Dehler, 2011; Engelmann \& Hesse, 2010; Fransen, Kirschner, \& Erkens, 2011). Some few studies have so far shown that this might have a positive effect (Geister, Konradt, \& Hertel, 2006; Martens, 2009; Zumbach, 2003; Zumbach, Reimann, \& Koch, 2006). Martens (2009) implemented motivation feedback in a university course on research methods. The participants worked in small groups in a problem-based learning scenario. In the experimental condition, the participants filled in a questionnaire on their motivation every week while the participants in the control condition did a general course evaluation without any reference to motivation. The participants of the experimental condition got feedback of their own individual data as well as the mean of the small group by means of a graphical display which also encompassed the data of the previous weeks. In both conditions, the participants discussed their evaluation. At the end of the semester, the students in the experimental condition who received motivation feedback showed a higher intrinsic motivation than the participants in the control condition.

A quite similar study was conducted by Zumbach (2003; Zumbach et al., 2006). He also implemented problem-based learning in a university course. Every 25 minutes, learning motivation was assessed while the students worked in groups of 3. In the experimental condition, the students received feedback on their participation, emotion, and motivation by 
means of a graphical display, whereas the students in the control condition got no feedback at all. At the end of the course, the students in the feedback condition reported a higher motivation. However, in this study the effects of feeding back both participation, emotion and motivation were confounded with each other.

Another study on feedback of motivation (Geister et al., 2006) originated from social and organizational psychology. Geister and colleagues (2006) implemented an onlinefeedback-system in virtual teams of students. This feedback system covered both motivation feedback, task-related feedback and relationship-related feedback. Geister et al. (2006) found positive effects of the feedback system on less motivated team members. However, also in this study the effects of feeding back several constructs were confounded.

There are several possible explanations why providing motivation feedback to the group members might have a positive effect on motivation. According to Zumbach (2003), this is due to a problem solving process within the group. If one group member is less motivated and this is visible in the feedback tool, the other group members get an opportunity to recognize this problem, address it and solve it. Geister et al. (2006) argue in a similar way: The feedback might focus the team members' attention to motivation which might trigger reflection and improvements. Moreover, Geister et al. (2006) suggest that an adjusted effort of the team members might be the cause for motivation improvements, or that there is no more need to fear the exploitation of their effort by the other group members. This would be a neutralization of the sucker effect (Kerr, 1983). The sucker effect refers to the phenomenon that a group member loses his/her motivation because another or all other group members are not motivated in which case our group member runs the risk of doing all the work alone, of being a sucker (Kerr, 1983).

When we disentangle the several aspects a feedback tool provides, we can list the following possible processes:

1) Filling in a questionnaire might trigger better self-reflection (c.f. Geister et al., 2006).

2) Receiving feedback of the own motivational data (for example as a graphical display) might also lead to a better self-reflection.

3) Receiving feedback about the motivation of the other group members might enable social comparison processes (Festinger, 1954) and therefore potentially an 
adjustment of effort might occur (Geister et al., 2006). Additionally, it might reduce the fear of being exploited by the other group members (Geister et al., 2006; Kerr, 1983).

4) Talking about potential motivational problems might remedy them (Zumbach, 2003) which might also be part of the group regulatory process (c.f. Martens, 2009).

This last process is also highlighted in the Dual-Loop Model of Social Regulation by Schoor, Narciss and Koerndle (2011). In their model, Schoor et al. (2011) describe the regulation of group learning (c.f. Hadwin, Järvelä, \& Miller, 2011; Volet, Vauras, \& Salonen, 2009). They assume two feedback loops: one referring to the learner, and an additional feedback loop referring to the group process. In the feedback loop referring to the learner, he/she processes internal feedback about her/his own learning process. Feedback about the group partner(s) is processed in the second feedback loop. Depending on the exact situation, the learner might react on this feedback by changing his/her own motivation or by trying to change the group partner's motivation (Schoor et al., 2011). Schoor et al. (2011) identified the opportunity to talk to the group partner as an essential component that influences which of these alternatives is chosen and therefore how the motivation of the group is affected.

\section{Objectives and hypotheses}

While Martens (2009) explicitly made the students talk about their feedback, in both the studies by Zumbach (2003; Zumbach et al., 2006) and Geister et al. (2006) we can only speculate about whether the students indeed discussed their motivation and thereby solved motivational problems. Therefore, it was the aim of the present research to closer investigate the conditions under which a positive effect of motivation feedback occurs. Specifically, we addressed the assumption that the group partners have to talk about the feedback for it to have a positive effect. Thus, we investigated the following hypotheses:

Hypothesis 1: After collaboration, groups with a feedback tool are more motivated than groups without a feedback tool.

Hypothesis 2: The increase of knowledge during collaboration is higher in groups with a feedback tool than in groups without a feedback tool.

Hypothesis 3: After collaboration, groups who talk about their motivation feedback are more motivated than groups who do not talk about their feedback or groups without a feedback tool. 


\section{Method}

\section{Participants}

Participants were 78 university first-year psychology students. They were 18 to 46 years old $(M=21.22, S D=4.73,88.5 \%$ female $)$ and received a certificate of 3 participanthours which they needed for their studies. The participants worked in triads. Six triads had to be excluded from the analysis due to technical problems for at least one of their members.

\section{Material and instruments}

Learning material and task. The collaborative learning task for the participants was to devise a "manual" for first-year students on how to benefit most from lectures. In order to do so, each member of a triad received a different textbook text on how to benefit from lectures. By not handing out the same text to all group members, we created resource interdependence (Johnson \& Johnson, 1992). Before reading the text, the participants were asked to discuss the relevance of lectures for their studies for half an hour. Then, they were told to read the text and to develop their "manual". For the collaboration, the participants had a chat tool and a shared editor at their disposal on the learning management system Moodle.

Tool for current motivation feedback. In the two feedback conditions, current motivation was assessed every 15 minutes via a popup questionnaire. The questionnaire consisted of four items by Schoor (2010) who used the three items of the questionnaire of current motivation by Vollmeyer and Rheinberg (2003) plus one additional item (e.g., "I enjoy this task very much."). The participants of both feedback conditions had to rate their motivation on a 7-point Likert scale. Cronbach's $\alpha$ for the four items was .82. A single value for current motivation was generated by averaging the rating of the four items. After all three members of a group had filled in the questionnaire, the tool showed a graphic of the current motivation of all three group members. Each member was represented in the graphic by a line over all measurement points so far. The line was labelled with the participant's nickname. The only difference between the two feedback conditions was that in the feedback plus discussion condition, the participants were asked to talk about the results for 5 minutes. The feedback without discussion condition got no such prompt. Figure 1 shows a screenshot of the feedback tool in the feedback plus discussion condition. 


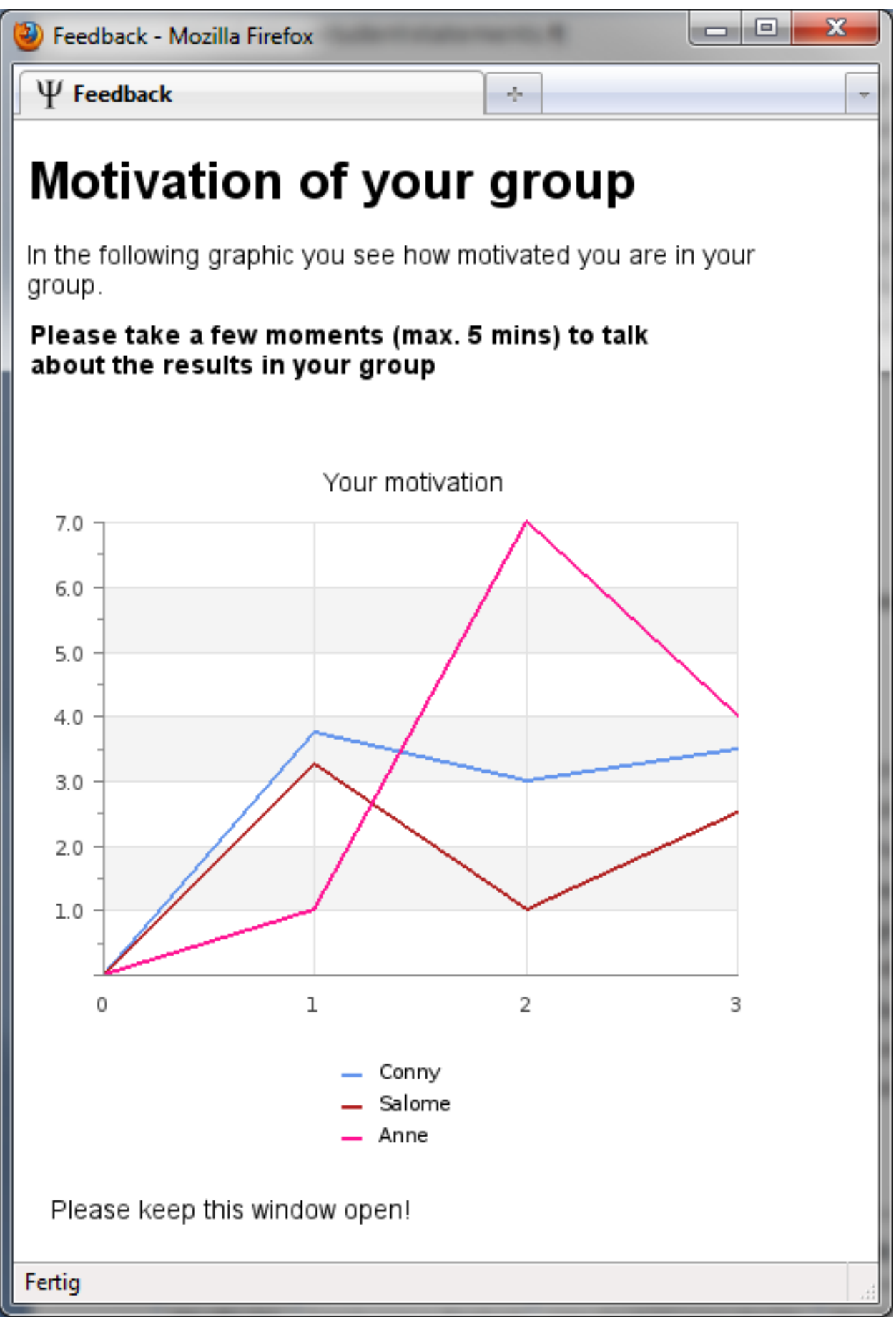

Figure 1. Screenshot of the Feedback Tool with Prompt to Discuss the Results (in Bold Type)

Motivation. Motivation was conceptualized within an expectancy-value framework (e.g., Eccles \& Wigfield, 2002; Pintrich, 2003). Within expectancy-value theory, motivation is believed to comprise several expectancy (e.g., self-efficacy) and value (e.g., intrinsic task value, attainment value) components. Motivation was assessed before and after the 
collaboration by means of an adjusted version of the expectancy-value-form by Puta, Narciss and Schnaubert (2012). This questionnaire contains 18 items on perceived competence, intrinsic value, attainment value and fear of failure. As their questionnaire was developed for the domain of fractions and measures motivation in a retrospective way, we had to adjust the items to the content domain (develop a manual for first-year students) and we adjusted the tense of the items we used for measuring motivation before the collaboration. Sample items are given in Table 1. The items were rated on a Likert scale ranging from 1 (not at all true) to 6 (perfectly true). The internal consistencies of these scales were good to very good except for perceived competence and attainment value before collaboration (see Table 1).

Table 1. Internal Consistencies (Cronbach's $\alpha$ ) of Motivation Scales Before and After Collaboration.

\begin{tabular}{lcccl}
\hline & $\#$ & $\mathrm{t}_{1}$ & $\mathrm{t}_{2}$ & Sample item \\
\hline perceived competence & 3 & .46 & .82 & I think I'll be very good in developing this manual. \\
intrinsic value & 6 & .90 & .92 & I will enjoy the joint problem solving process. \\
attainment value & 5 & .46 & .71 & It is very important to me to develop a good manual. \\
fear of failure & 4 & .77 & .85 & I fear making mistakes, even if nobody would notice \\
& & & & it.
\end{tabular}

Note. $\#=$ number of items

$\mathrm{t}_{1}=$ before collaboration

$\mathrm{t}_{2}=$ after collaboration

Knowledge. Both prior and post knowledge test consisted of several multiple choice questions on the content of the textbook tests. Each question had four to six alternative answer options of which none, one, several or all could be correct. A point was scored for the correct pattern of answers per question. The questions were different for prior respectively post knowledge test. The prior knowledge test contained nine questions (e.g., "What are minimum 'to-dos' for effectively attending a lecture?’), the post knowledge test contained 12 questions (e.g., "How much is the ideal amount of time for preparing and reinforcing the topics of a lecture?"). Item difficulties ranged from .20 to .50 in the prior knowledge test respectively from .20 to .82 in the post knowledge test.

Control variable: Need for cognition. Need for cognition is a concept that "refers to an individual's tendency to engage in and enjoy effortful cognitive endeavors" (Cacioppo, Petty, $\&$ Kao, 1984, p. 306). As working on the topic of how to benefit most from lectures might be influenced by the need for cognition of the participant, we additionally assessed need for 
cognition as a control variable. Therefore, we used the short scale by Bless, Wänke, Bohner, Fellhauer and Schwarz (1994) that consists of 16 items. The items were rated on a Likert scale ranging from 1 (not at all true) to 6 (perfectly true). The internal consistency of this scale reached a Cronbach's $\alpha$ of .81 .

\section{Procedure}

The study was conducted in three rooms. The participants were tested in groups of up to 12 people ( 4 triads) at the same time. The members of a triad worked in different rooms (so they could communicate only via computer) and did not know each other before the collaboration. At the beginning of the study, the participants received a general introduction and filled in questionnaires on demographics, prior knowledge and need for cognition (control variable). After being informed about the task and the computer tool used for the collaboration with their group members, motivation was assessed. Then, the collaboration started. First, the participants chose a nickname for the collaboration. The participants' task was to devise a "manual" for first-year students on how to benefit most from lectures. During the task, the participants in the two feedback conditions regularly filled in a short questionnaire on motivation and got feedback about it. The participants in the control condition did not fill in the questionnaire and received no feedback. The participants worked about 1.5 hours on the task. Then, they were told to finish the task and to fill in the post questionnaires on motivation and knowledge.

\section{Design and Statistical Analysis}

The participants were randomly assigned to one of three conditions: 1 . With feedback tool and prompt to discuss the results (feedback plus discussion condition), 2. With feedback tool without a prompt to discuss (feedback only condition), and 3. Without feedback tool (control condition).

Due to the small sample size, we decided to analyse the data on the level of the individual. This procedure can overestimate effects if the intra-class correlation (ICC) of triads is high (Cress, 2008). Therefore, we checked the ICCs. They were all not significantly different from zero, which means that possible effects are probably not overestimated when analysed at the individual level. Table 2 displays the exact values. 


\section{Table 2. Intra-Class-Correlation (ICC) of the Dependent Variables After Collaboration Within Triads.}

\begin{tabular}{lc} 
& ICC \\
\cline { 2 - 2 } perceived competence & -.14 \\
intrinsic value & -.02 \\
attainment value & -.08 \\
fear of failure & -.09 \\
post knowledge & .11
\end{tabular}

Note. We report the ICC suggested by Shrout and Fleiss (1979) as ICC (1,1).

\section{Results}

\section{Manipulation check}

We first inspected the chat protocols in order to find out whether the participants in the two feedback conditions discussed their results or not. We included in the feedback plus discussion condition those triads of both experimental conditions who actually discussed their feedback at least twice ( $N=18 ; 6$ triads). To the feedback without discussion condition we assigned triads who never discussed their feedback ( $N=15 ; 5$ triads).

\section{Preliminary analyses}

Before the main analyses, we checked on a priori difference between the conditions (see Table 3 for descriptive statistics). There were no significant differences between the conditions neither regarding prior knowledge $\left(F(2,48)=2.07, p=.14, \eta_{\mathrm{p}}{ }^{2}=.08\right)$ nor need for cognition $\left(F(2,48)=1.75, p=.18, \eta_{\mathrm{p}}^{2}=.07\right)$ nor motivation $\left(F(8,92)=0.88, \mathrm{p}=.54, \eta_{\mathrm{p}}^{2}=\right.$ $.07)$. 
Table 3. Means (and Standard Deviations) of Conditions Regarding Dependent and Control Variables.

\begin{tabular}{lccccc}
\hline & Scale & control & feedback & feedback & feedback \\
condition & without & plus & overall \\
& & $\mathrm{N}=18$ & discussion & discussion & $\mathrm{N}=42$ \\
& & & $\mathrm{~N}=15$ & $\mathrm{~N}=18$ & \\
\hline Need for cognition & $1-6$ & $4.51(0.44)$ & $4.20(0.48)$ & $4.41(0.50)$ & $4.33(0.51)$ \\
Prior knowledge & $\leq 9$ & $3.11(1.28)$ & $2.33(1.50)$ & $2.22(1.48)$ & $2.50(1.55)$ \\
Post knowledge & $\leq 12$ & $4.72(2.16)$ & $5.60(2.35)$ & $5.11(1.36)$ & $5.14(2.10)$ \\
Prior motivation & & & & & \\
$\quad \begin{array}{l}\text { perceived competence } \\
\text { intrinsic value }\end{array}$ & $1-6$ & $3.52(0.50)$ & $3.60(0.58)$ & $3.72(0.45)$ & $3.65(0.49)$ \\
$\quad 1-6$ & $3.60(0.79)$ & $3.51(0.94)$ & $3.84(0.67)$ & $3.77(0.81)$ \\
attainment value & $1-6$ & $3.78(0.36)$ & $3.92(0.59)$ & $4.03(0.48)$ & $4.01(0.48)$ \\
$\quad$ fear of failure & $1-6$ & $3.28(0.65)$ & $3.62(0.72)$ & $3.32(0.79)$ & $3.46(0.85)$ \\
Post motivation & & & & & \\
$\quad \begin{array}{l}\text { perceived competence } \\
\text { intrinsic value }\end{array}$ & $1-6$ & $3.93(0.73)$ & $4.24(1.17)$ & $4.07(0.64)$ & $4.04(1.00)$ \\
attainment value & $1-6$ & $4.64(0.47)$ & $4.31(1.24)$ & $4.42(0.60)$ & $4.45(0.91)$ \\
fear of failure & $1-6$ & $4.04(0.59)$ & $4.09(0.79)$ & $4.20(0.64)$ & $4.17(0.65)$ \\
\hline & $1-6$ & $2.86(0.90)$ & $3.13(1.02)$ & $2.93(0.81)$ & $3.03(0.93)$ \\
\hline
\end{tabular}

Hypothesis 1: Higher motivation with a feedback tool

The first hypothesis was that participants in the feedback conditions are more motivated after collaboration than participants without a feedback tool. While the motivation increased over time (with the exception of fear of failure which decreased), there was no differential effect in the conditions (c.f. Table 3).

We conducted a repeated measures multivariate analysis of variance with the four constructs of motivation as dependent variables and a factor coding the presence or absence of the feedback tool as an independent variable. We found no effect of the presence of the feedback tool $\left(F(1,58)=0.98, p=.33, \eta_{\mathrm{p}}{ }^{2}=.02\right)$ or any interaction of it with time $(F(1,58)=$ $\left.1.14, p=.29, \eta_{\mathrm{p}}{ }^{2}=.02\right)$, with motivation construct $\left(F(3,174)=0.29, p=.83, \eta_{\mathrm{p}}{ }^{2}=.01\right)$ or with both $\left(F(3,174)=0.80, p=.49, \eta_{\mathrm{p}}{ }^{2}=.01\right)$. Therefore, hypothesis 1 had to be rejected. 


\section{Hypothesis 2: Better achievement with a feedback tool}

The second hypothesis was that, resulting from higher motivation of the participants in the feedback conditions, they would also perform better. Although the participants with the feedback tool performed slightly better in the post knowledge test (c.f. Table 3), this difference was not significant. Including prior knowledge into an analysis of covariance also revealed no significant differences $\left(F(2,57)=1.53, p=.23, \eta_{\mathrm{p}}{ }^{2}=.05\right)$.

\section{Hypothesis 3: Discussion of feedback}

As not the mere presence of the feedback tool but only the discussion about it might have had the expected positive effect on motivation, we tested whether there was any difference in motivation and post knowledge in the feedback plus discussion condition compared to the control condition. Regarding motivation, the repeated measures multivariate analysis of variance revealed again no effect of the feedback $\left(F(1,34)=0.78, p=.38, \eta_{\mathrm{p}}{ }^{2}=\right.$ $.02)$ or any interaction of it with time $\left(F(1,34)=1.85, p=.18, \eta_{\mathrm{p}}{ }^{2}=.05\right)$, with motivation construct $\left(F(3,102)=0.32, p=.81, \eta_{\mathrm{p}}^{2}=.01\right)$ or with both $\left(F(3,102)=1.54, p=.21, \eta_{\mathrm{p}}{ }^{2}=\right.$ $.04)$.

As for differences in the conditions with feedback plus discussion versus without discussion, the results were similar. There was no effect of the feedback condition $(F(1,31)=$ $\left.0.01, p=.94, \eta_{\mathrm{p}}{ }^{2}=.00\right)$ or any interaction of it with time $\left(F(1,31)=0.43, p=.52, \eta_{\mathrm{p}}{ }^{2}=.01\right)$, with motivation construct $\left(F(3,93)=1.08, p=.36, \eta_{\mathrm{p}}{ }^{2}=.03\right)$ or with both $(F(3,93)=0.62, p$ $\left.=.61, \eta_{\mathrm{p}}^{2}=.02\right)$.

\section{Additional analyses}

Moderators: Need for cognition and prior knowledge. Additionally, we checked whether need for cognition or prior knowledge was a moderator of the motivational effects of the feedback tool. In order to do that, we included an interaction term of condition by moderator into a multivariate analysis of covariance with the difference value of motivation in the post and pretest as dependent variable. However, we found neither an effect for the moderator need for cognition $\left(F(8,86)=0.31, p=.96, \eta_{\mathrm{p}}^{2}=.03\right)$ nor for prior knowledge as moderator $\left(F(8,86)=0.85, p=.57, \eta_{\mathrm{p}}^{2}=.07\right)$. 
Least motivated group members. As Geister et al. (2006) found only an effect of their feedback tool on the less motivated members of each group, we tested this as well. Therefore, we built a sum score on motivation in the pretest (fear of failure was recoded). Then, we coded for each participant whether (s)he was the most, middle or least motivated group member within their group. For the least motivated members of each group, we investigated the posttest motivation scores and post knowledge scores (see Table 4). A multivariate analysis of variance with the four motivation constructs as dependent variables and the condition as independent variable revealed no significant difference between the conditions $\left(F(8,24)=0.87, p=.56, \eta_{\mathrm{p}}{ }^{2}=.22\right)$. There were no differences in the post knowledge score (while taking prior knowledge as covariate into account) either $\left(F(3,13)=0.54, p=.66, \eta_{\mathrm{p}}{ }^{2}=\right.$ $.11)$.

Table 4. Knowledge and Motivation Scores of the Lowest Motivated Member of Each Group.

\begin{tabular}{|c|c|c|c|c|}
\hline & Scale & $\begin{array}{c}\text { control } \\
\text { condition } \\
\mathrm{N}=6\end{array}$ & $\begin{array}{l}\text { feedback } \\
\text { without } \\
\text { discussion } \\
\mathrm{N}=5\end{array}$ & $\begin{array}{c}\text { feedback } \\
\text { plus } \\
\text { discussion } \\
\mathrm{N}=6\end{array}$ \\
\hline Prior knowledge & $\leq 9$ & $3.00(1.67)$ & $2.20(1.30)$ & $2.17(1.60)$ \\
\hline Post knowledge & $\leq 12$ & $4.67(2.16)$ & $4.40(2.61)$ & $5.00(2.83)$ \\
\hline \multicolumn{5}{|l|}{ Post motivation } \\
\hline perceived competence & $1-6$ & $3.50(0.94)$ & $3.60(0.81)$ & $4.06(0.71)$ \\
\hline intrinsic value & $1-6$ & $4.61(0.53)$ & $3.67(1.59)$ & $3.97(0.56)$ \\
\hline attainment value & $1-6$ & $3.80(0.63)$ & $3.60(0.81)$ & $3.73(0.67)$ \\
\hline fear of failure & $1-6$ & $3.58(0.86)$ & $2.95(1.41)$ & $3.13(1.01)$ \\
\hline
\end{tabular}

\section{Discussion}

In this study, the effects of providing motivation feedback to the group partners in computer-supported collaborative learning, and specifically the effect of the group partners talking about this feedback, were investigated. First, we wanted to show that motivation feedback increases the motivation of the group and leads to better knowledge acquisition. However, there was no advantage of the feedback tool compared to a control condition without a feedback tool neither regarding motivation nor regarding knowledge acquisition. 
This was still the case when we took prior knowledge, prior motivation or need for cognition as moderators into account.

In a second question, we focused on the assumed process of discussing the motivation feedback as central mechanism of the feedback effect (Schoor et al., 2011; Zumbach, 2003). Also in regard to this question, the hypothesis could not be confirmed. However, this could also be due to the non-existing overall effect of motivation feedback. Only if we know what circumstances are needed for a positive effect of motivation feedback, then we can further research the assumed processes that bring this effect about.

Therefore, we must conclude that in our study providing motivation feedback to the group partner had no influence on computer-supported collaborative learning. Further, the results by Martens (2009), Zumbach (2003; Zumbach et al., 2006) and Geister et al. (2006) could not be replicated.

Several aspects might be responsible for this: First, we investigated motivation feedback in a short-term scenario covering only 2 hours of collaborative work. Martens (2009), who alone found unconfounded effects of motivation feedback, used a scenario covering several weeks. Geister et al. (2006) also conducted a longitudinal study. In the case of Zumbach, there was a short-term (Zumbach et al., 2006) and a long-term study (Zumbach, 2003). However, in their studies motivation feedback was confounded with feedback of other constructs. Therefore, effects of motivation feedback might be confined to long-term scenarios.

A second explanation might be the interruption of the collaboration every 15 minutes. This might have been too often and thereby deterred motivation. Such a negative motivational effect might have cancelled out any positive effects of the feedback. This might also be the reason why a positive feedback effect might occur only in long-term scenarios: Naturally, the different assessment occasions in a long-term scenario are further apart from each other.

Additionally, the topic of the students' task was very relevant for them and they had no pressure to perform well in the task as this was neither part of their studies nor did they receive a grade for their work. Therefore, there might not have been any motivational 
problems at all. Without this challenge, there might have been no need to regulate the group's motivation (c.f. McCardle, Helm, Hadwin, Shaw, \& Wild, 2011).

Another explanation is derived from the Dual-Loop Model of Social Regulation (Schoor et al., 2011): The learners need an (internal) reference value in order to detect discrepancies of current motivation and desired motivation. If they do not have a clear reference value of how the motivation of a group should be, this might be the reason why they did not react on the feedback they received. Therefore, the implicit reference value of the learners could either be assessed or explicitly set by instructions in future studies.

Therefore, it has to be clarified in further studies what the constitutive factors are for a positive effect of providing motivation feedback to a group. As discussed above, it remains a question whether only long-term collaborations profit from this kind of feedback or whether this is also true for short-term collaborations. Furthermore, it has to be closer investigated what kind of role the content plays, and whether motivational problems are a necessary condition for positive feedback effects. Additionally, the setting of a concrete reference value for the group's motivation might be necessary. A limitation of this study is that motivation was assessed only by means of self-report data. In further studies, behavioral data could be used in addition. These behavioral data could be, for example, decisions whether to continue or to quit the learning process (c.f. Ainley, Hillman, \& Hidi, 2002). When these questions are answered, this would also help develop a more elaborated theoretical framework. The framework by Schoor et al. (2011) provides an overview of the processes involved, but it has to be supported by empirical results for each of these processes.

A mere statistical limitation of this study is the comparatively small sample size. With larger sample sizes, procedures like multi-level modelling might be taken into account (c.f. Cress, 2008). However, as our procedure of using individual data should have overestimated possible effects (Cress, 2008), this is unlikely to be the reason for our unexpected results.

A practical implication of this study is that in short-term collaboration, it might not be necessary to support collaborative learning groups with a motivation feedback tool, at least if the topic is relevant for the students. The results in our study indicate that the motivation of the group members could not be enhanced in a substantial way. However, this might be 
different in either a long-term setting or a setting with a different and maybe more boring task for the students.

\section{References}

Ainley, M., Hillman, K., \& Hidi, S. (2002). Gender and interest processes in response to literary texts: situational and individual interest. Learning and Instruction, 12(4), 411-428.

Bless, H., Wänke, M., Bohner, G., Fellhauer, R. F., \& Schwarz, N. (1994). Need for Cognition: Eine Skala zur Erfassung von Engagement und Freude bei Denkaufgaben [Need for Cognition: A scale for the assessment of involvement and happiness in cognitive tasks]. Zeitschrift für Sozialpsychologie, 25, 147-154.

Bodemer, D., \& Dehler, J. (2011). Group awareness in CSCL environments. Computers in Human Behavior, 27(3), 1043-1045.

Cacioppo, J. T., Petty, R. E., \& Kao, C. F. (1984). The efficient assessment of need for cognition. Journal of Personality Assessment, 48(3), 306-307.

Cress, U. (2008). The need for considering multilevel analysis in CSCL research - An appeal for the use of more advanced statistical methods. International Journal of ComputerSupported Collaborative Learning, 3(1), 69-84.

Eccles, J. S., \& Wigfield, A. (2002). Motivational beliefs, values, and goals. Annual Review of Psychology, 53(1), 109-132.

Engelmann, T., \& Hesse, F. (2010). How digital concept maps about the collaborators' knowledge and information influence computer-supported collaborative problem solving. International Journal of Computer-Supported Collaborative Learning, 5(3), 299319. doi: 10.1007/s11412-010-9089-1

Festinger, L. (1954). A theory of social comparison processes. Human Relations, 7(2), 117140.

Fransen, J., Kirschner, P. A., \& Erkens, G. (2011). Mediating team effectiveness in the context of collaborative learning: The importance of team and task awareness. Computers in Human Behavior, 27(3), 1103-1113. doi: 10.1016/j.chb.2010.05.017

Geister, S., Konradt, U., \& Hertel, G. (2006). Effects of process feedback on motivation, satisfaction, and performance in virtual teams. Small group research, 37(5), 459-489.

Hadwin, A. F., Järvelä, S., \& Miller, M. (2011). Self-regulated, co-regulated, and socially shared regulation of learning. In B. J. Zimmerman \& D. H. Schunk (Eds.), Handbook of self-regulation of learning and performance (pp. 65-84). New York: Routledge. 
Hron, A., Hesse, F. W., \& Friedrich, H. F. (2002). Gemeinsam lernt es sich besser: Kooperatives Lernen und kognitive Prozesse in netzbasierten Szenarien [Cooperative learning and cognitive processes in net-based scenarios]. In U. Scheffer \& F. W. Hesse (Eds.), E-Learning. Die Revolution des Lernens gewinnbringend einsetzen (pp. 83-100). Stuttgart: Klett-Cotta.

Johnson, D., \& Johnson, R. (1992). Positive interdependence: Key to effective cooperation. In R. Hertz-Lazarowitz \& N. Miller (Eds.), Interaction in cooperative groups. The theoretical anatomy of group learning (pp. 174-199). New York: Cambridge University Press.

Karau, S. J., \& Williams, K. D. (1993). Social loafing: A meta-analytic review and theoretical integration. Journal of Personality and Social Psychology, 65(4), 681-706.

Kerr, N. L. (1983). Motivation losses in small groups: A social dilemma analysis. Journal of Personality and Social Psychology, 45(4), 819-828.

Kreijns, K., Kirschner, P. A., \& Jochems, W. (2003). Identifying the pitfalls for social interaction in computer-supported collaborative learning environments: A review of the research. Computers in Human Behavior, 19(3), 335-353.

Linnenbrink-Garcia, L., Rogat, T., \& Koskey, K. (2011). Affect and engagement during small group instruction. Contemporary Educational Psychology, 36(1), 13-24.

Martens, T. (2009). Unterstützung der intrinsischen Motivation beim Lernen von Methodenlehre in Gruppen mit Hilfe von Online-Monitoring [Support of intrinsic motivation during the learning of methods in groups via online monitoring]. In M. Kraemer, S. Preiser \& K. Brusdeylins (Eds.), Psychologiedidaktik und Evaluation VII (pp. 265-276). Aachen: Shaker.

McCardle, L., Helm, S., Hadwin, A. F., Shaw, K., \& Wild, P. (2011). Regulation of learning in the context of collaborative challenges. Poster presented at the EARLI, Exeter, UK.

Pintrich, P. R. (2003). Motivation and classroom learning. In W. Reynolds \& G. Miller (Eds.), Handbook of Psychology: Educational Psychology (Vol. 7, pp. 103-122). Hoboken, NJ: Wiley \& Sons.

Puta, M., Narciss, S., \& Schnaubert, L. (2012). Erwartungs-Wert-Fragebogen zur bereichsspezifischen Lernmotivation (EWF-LM): psychometrische Eigenschaften und offene Fragen [Expectancy-Value-Form to assess domain-specific learning motivation (EWF-LM): Psychometric properties and open questions]. Manuscript submitted for publication. 
Schoor, C. (2010). Die Bedeutung von Motivation für Wissenserwerbsprozesse beim computerunterstützten kooperativen Lernen [The importance of motivation for knowledge acquisition processes during computer-supported collaborative learning]. Berlin: Logos.

Schoor, C., Narciss, S., \& Koerndle, H. (2011). Motivation regulation in groups: Theoretical considerations about the learning partner's motivation. Paper presented at the EARLI, Exeter, $U K$.

Shepperd, J. A. (1993). Productivity loss in performance groups: A motivation analysis. Psychological Bulletin, 113(1), 67-81.

Slavin, R. (1992). When and why does cooperative learning increase achievement? Theoretical and empirical perspectives. In R. Hertz-Lazarowitz \& N. Miller (Eds.), Interaction in cooperative groups: the theoretical anatomy of group learning (pp. 145-173). Cambridge: University Press.

Volet, S., Vauras, M., \& Salonen, P. (2009). Self- and social regulation in learning contexts: An integrative perspective. Educational Psychologist, 44(4), 215-226.

Vollmeyer, R., \& Rheinberg, F. (2003). Aktuelle Motivation und Motivation im Lernverlauf [Current motivation and motivation in the course of learning]. In J. StiensmeierPelster \& F. Rheinberg (Eds.), Diagnostik von Motivation und Selbstkonzept (pp. 281295). Göttingen: Hogrefe.

Zumbach, J. (2003). Problembasiertes Lernen [Problem-based learning]. Münster: Waxmann.

Zumbach, J., Reimann, P., \& Koch, S. C. (2006). Monitoring students' collaboration in computer-mediated collaborative problem-solving: Applied feedback approaches. Journal of Educational Computing Research, 35(4), 399-424. 
Cornelia Schoor et al.

[This page intentionally left blank] 